Article

\title{
Extending the Theory of Planned Behavior to Explain the Effects of Cognitive Factors across Different Kinds of Green Products
}

\author{
Leibao Zhang ${ }^{1}$, Yanli Fan ${ }^{1,3}$, Wenyu Zhang ${ }^{2, *}$ and Shuai Zhang ${ }^{2}$ \\ 1 School of Public Finance and Taxation, Zhejiang University of Finance and Economics, \\ Hangzhou 310018, China \\ 2 School of Information, Zhejiang University of Finance and Economics, Hangzhou 310018, China \\ 3 School of Public Finance and Administration, Shanghai University of Finance and Economics, \\ Shanghai 200433, China \\ * Correspondence: wyzhang@e.ntu.edu.sg
}

Received: 28 June 2019; Accepted: 2 August 2019; Published: 5 August 2019

check for updates

\begin{abstract}
Sustainable development is a powerful impetus to achieve the coordination between economic advancement and environmental protection. Therefore, the promotion and adoption of green consumption has attracted increasing attention from academics. As an important tool for multivariate data analyses, structural equation modelling has been extensively used in purchase intention for green products. However, most previous research has recognized green products as a general class when studying their purchase intention, which focused little attention on comparing purchase intention for different kinds of green products. This study extends and tests the theory of planned behavior (TPB) and includes another cognitive construct, that is, environmental concern, to explore purchase intention for different kinds of green products. First, the effect of TPB constructs was examined on purchase intention for utilitarian green products and hedonic green products. Second, a cognitive factor, that is, environmental concern, was used to test its different effects on these two kinds of green products. Third, the indirect effect of environmental concern on purchase intention was measured for these two kinds of green products. The study showed that extended TPB constructs, that is, attitude, perceived behavior control, and environmental concern positively and significantly affected purchase intention for both utilitarian green products and hedonic green products, while subjective norm only significantly and positively affected purchase intention for utilitarian green products. Moreover, the cognitive factor, that is, environmental concern, had a higher effect on purchase intention for utilitarian green products than purchase intention for hedonic green products, and it also had a similar indirect effect on both kinds of green products. This study provides an insight to policymakers, entrepreneurs, and marketers into how to increase purchase intention for different kinds of green products.
\end{abstract}

Keywords: purchase intention; cognitive factor; environmental concern; extended theory of planned behavior; utilitarian green products; hedonic green products

\section{Introduction}

With increasing resource constraints, environmental pollution, and ecological degradation, environmental problems have attracted increasing attention from academicians, policymakers, and marketers [1]. Environmental protection has become an urgent problem that cannot be avoided and ignored in the economic development of a country or a region. Previous studies have shown that unreasonable consumption habits and patterns have been one of the most influential factors for the 
environment and caused nearly $40 \%$ of environmental degradation [2]. Therefore, promotion and adoption of green consumption has an imperative effect on solving environmental problems.

Green products are the products that can be recycled or reused, and they will not pollute the earth or waste natural resources [3]. Green consumption has gradually become a consumption trend with the improvement of living standards. Meanwhile, the research on green consumption has increasingly attracted the attention of researchers. Many previous studies have explored purchase intention for green products and further studied purchase behavior for green products [4-6]. Various conceptual frameworks such as the construal level theory (CLT) [7], the theory of reasoned action (TRA) [8], and the social cognitive theory (SCT) [9] have been studied in the field of green consumption and achieved good results. Moreover, another conceptual framework, the theory of planned behavior (TPB) [10], has been extensively used and extended in green consumption because of its good applicability and extensibility [11-13].

TPB is an extensively used theory in purchase intention for green products $[4,11,14,15]$. It can be used for exploring the effect of attitude, subjective norms, and perceived behavior control on purchase intention for green products from a psychological perspective. Owing to its adaptive ability, TPB and various extended forms have been proposed to explore purchase intention for green products. For example, Chen and Hung combined TPB with social impression, environmental consciousness, and environmental ethics and beliefs to predict adoption intention for green products [16]. Sreen et al. included collectivism, long-term orientation, and man-nature orientation dimensions into the TPB framework to investigate individual green purchase intention [17].

Although previous studies have used and extended TPB in several aspects for exploring purchase intention for green products, there are still a lot of limitations that remain to be solved. On the one hand, few researchers have considered the different effects of constructs on purchase intention for different kinds of green products. On the other hand, little of the literature has elaborated on how cognitive factors affect purchase intention for utilitarian green products and hedonic green products, which are divided based on different purchase motives. These limitations drive the possibilities for further exploration in green consumption. Therefore, the present research has used the TPB as conceptual framework and further attempted to include a cognitive construct (i.e., environmental concern) to measure its effect on purchase intention for different kinds of green products. First, the direct effect of TPB constructs (i.e., attitude, subjective norms, and perceived behavior control) has been verified on different kinds of green products (i.e., utilitarian green products and hedonic green products). Second, a cognitive factor (i.e., environmental concern) has been used to compare its different effects on purchase intention for utilitarian green products and hedonic green products. Third, this study has measured the indirect effect of the cognitive factor, which examines the effect of environmental concern on purchase intention for different green products through other constructs (i.e., attitude, subjective norms, and perceived behavior control). Furthermore, structural equation modeling (SEM) has been widely used in psychology and behavior science. Therein, covariance-based SEM and variance-based/component-based SEM are two prevalent methods. This study adopted component-based SEM that uses a least squares estimation procedure, because of its great suitability to smaller sample size. This study makes a research contribution in exploration of the purchase intention for different kinds of green products by presenting, and then testing, the effect of the extended TPB and cognitive factors on utilitarian green products and hedonic green products.

The remainder of this paper is organized as follows: Section 2 provides an overview of related literature and hypotheses are developed based on previous research. Section 3 introduces, in detail, the methodology and measurement used in this study. Section 4 elaborates on the data analysis process to verify the reliability and validity of the method used, and evaluates the obtained prediction results. Section 5 introduces some discussion of the findings and implications of this study. Section 6 describes the limitations and future research scope. 


\section{Literature Review and Hypotheses Development}

\subsection{Theory of Planned Behavior}

TPB is a prevalent theory in psychology and behavior science. TPB was first developed and used by Ajzen [10]. It indicates that individual behavior is driven by behavioral intentions, which are a function of three independent constructs (i.e., attitude toward behavior, subjective norms, and perceived behavioral control) [18]. It has been widely used and extended in many studies, such as new system adoption behavior [19], e-service usage [20], oil palm smallholder planters' intention [21], microblogging intention [22], and purchase intention for organic clothing [23] and energy-efficient appliances [24].

\subsubsection{Theory of Planned Behavior in Purchase Intention for Green Products}

Increasingly severe environmental problems have gradually aroused the environmental protection concern of society and it is believed that humans and human behaviors have an important impact on the environment. As indicated by Eagly and Chaiken [18], individual behavior is driven by behavioral intentions, so research about purchase intention for green products has been developed to reflect green products purchase behavior and give implications to environmental protection [25]. TPB is an extensively used theory in purchase intention for green products [11,15]. Wu and Chen adopted six independent variables to measure their direct effect on three major constructs in TPB and their mediating effects on purchase intention for green products [12]. Chen and Hung combined TPB with three other constructs to predict customer intention to adopt green products [16]. Yadav and Pathak extended TPB and found that environmental concern and environmental knowledge have a significant and positive effect on purchase intention for eco-friendly products [13]. Sreen et al. included collectivism, long-term orientation, and man-nature orientation dimensions in the TPB and used gender as the moderating variable to investigate individual green purchase intentions [17].

Green products is a comprehensive concept that contains various kinds of products, such as electric vehicles, energy efficient household appliances, and reusable shopping bags. All of the aforementioned research regard green products as a general class without considering different effects of constructs on different kinds of green products. Therefore, some researchers have explored the adoption of TPB/extended TPB for a specific green product. Zhou et al. applied a case of organic food, which is recognized as a classical green product, to study the indirect effect of personal values under the framework of extended TPB [26]. Nguyen et al. investigated the impacts of consumers' biospheric values on purchase behavior for energy efficient household appliances. In this research, energy efficient household appliances are a representative of green products [27]. Hsu et al. applied TPB to explore the effect of its main constructs on purchase intention for green skincare products and further measured the moderating effect of another two variables [15]. The same constructs can generate different effects on different green products, such as significant effect or insignificant effect, higher effect or lower effect. Brijs et al. pointed out that cognitive factors can better form the purchase intention for utilitarian-oriented products than hedonic-oriented products, but affective factors are on the contrary [28]. Purchase motives of utilitarian-oriented products (e.g., household appliances) are utilitarian reasons, and the purchase motives of hedonic-oriented products (e.g., clothing) are hedonic motives [29].

Therefore, this study aimed at investigating different effects of cognitive factors (e.g., environmental concern) between green utilitarian-oriented products (e.g., energy efficient household appliances) and green hedonic-oriented products (e.g., organic clothing) using extended TPB. It not only extends the standard TPB by adding a cognitive factor, that is, environmental concern, but also reveals the different effects of environmental concern on different kinds of green products.

\subsubsection{Attitude toward Green Products}

Attitude is one of the specific constructs in the framework of TPB. Eagly and Chaiken defined attitude as a psychological path that an individual can consistently favor or disfavor to a specific 
object [30]. Many previous researchers have studied the interrelationship between attitude and purchase intention for green products and concluded that attitude is an indispensable variable while predicting consumers' purchase intention. In these studies, attitude can mainly be divided into two types, one is general attitude, and the other is specific attitude. General attitude in these studies indicates the attitude toward environmental problems, and specific attitude indicates the attitude toward green products or a specific green product $[4,14,27]$. These two types of attitude were both widely discussed in many previous studies. However, various research has demonstrated that specific attitude is more likely to manifest in green behavior [27,31]. Han et al. found that a tourist who thinks selecting a green hotel is beneficial to environmental protection will tend to choose a green hotel [32]. Zhou et al. developed hypotheses based on previous literature and applied them to a case of organic food in China to study the effect of extended TPB on consumers' intention to buy organic food [26]. Chen and Tung concluded that individuals who have positive specific attitude toward visiting green hotels are more likely to choose green hotels in practice [33]. Paul et al. revealed that specific attitude toward purchasing green products is positively associated with purchase intention for green products [34]. Therefore, this study applied specific attitude toward green products to explore the interrelationship between attitude and purchase intention for green products.

Attitude, as one of the major constructs in TPB, has been extensively studied in previous research about purchase intention for green products. In addition, various empirical research has verified that attitude positively affects purchase intention for green products $[17,35,36]$. Yazdanpanah and Forouzani empirically examined the effectiveness of TPB framework and found that all constructs of TPB were significantly and positively related to purchase intention for organic food [37]. Kumar et al. constructed a conceptual framework and concluded that attitude is directly and positively related to purchase intention for the environmentally sustainable products [5]. The following hypotheses were developed based on the aforementioned research:

Hypothesis 1a (H1a). Attitude toward green products is positively and significantly associated with purchase intention for energy efficient household appliances.

Hypothesis $\mathbf{1 b} \mathbf{( H 1 b ) . ~ A t t i t u d e ~ t o w a r d ~ g r e e n ~ p r o d u c t s ~ i s ~ p o s i t i v e l y ~ a n d ~ s i g n i f i c a n t l y ~ a s s o c i a t e d ~ w i t h ~ p u r c h a s e ~}$ intention for organic clothing.

\subsubsection{Subjective Norm}

Subjective norm is defined as the perceived social pressure from people important to an individual to do or not to do a specific behavior [10]. In modern society, no one can separate from the society and become an independent individual, so word of mouth is one of the key factors affecting individual pro-environmental behaviors [38]. The majority of previous researchers have empirically explored the effect of subjective norms on purchase intention for green products using TPB [12,17,37]. Thøgersen found that subjective social norms are directly and positively related to pro-environmental behaviors [39]. Wu and Man used TPB framework to find that subjective norms have a positive effect on customers' intention to visit a green hotel [40]. Yadav and Pathak found that subjective norms positively influence the consumers' purchase intention for green products [13]. The following hypotheses were developed based on the aforementioned research:

Hypothesis 2a (H2a). Subjective norms are positively and significantly associated with purchase intention for energy efficient household appliances.

Hypothesis $\mathbf{2 b} \mathbf{b} \mathbf{H} \mathbf{2 b})$. Subjective norms are positively and significantly associated with purchase intention for organic clothing. 


\subsubsection{Perceived Behavior Control}

Perceived behavior control, as an important part of TPB, is defined as the ease or difficulty to perform a behavior [41]. In previous research, perceived behavior control was reflected by different aspects, such as perceived inconvenience, cost of time, and resources [42,43]. Wang et al. developed the hypotheses based on previous literature and concluded that perceived behavior control has a positive and significant effect on sustainable consumption behaviors, using the data from a survey in China [42]. Camilla and Patrick found that perceived inconvenience is often negatively related to purchase intention for eco-friendly products [43]. Similar results were concluded by Nguyen et al. [27]. Bong and Jin demonstrated that stronger perceived behavior control leads to a more positive intention to purchase green apparel products [44]. However, some researchers found a different association between perceived behavior control and purchase intention for green products. Arvola et al. uncovered that perceived behavior control and purchase intention for green products are not related based on empirical research [45]. These contrasting views lead to an inconsistent conclusion, necessitating further discussion on perceived behavior control. Based on previous research, this study considered that the stronger the perceived behavior control is, the more confidence an individual has to do a specific behavior, so the following hypotheses were developed, like the most of previous research:

Hypothesis 3a (H3a). Perceived behavior control is positively and significantly associated with purchase intention for energy efficient household appliances.

Hypothesis $\mathbf{3 b} \mathbf{b} \mathbf{H} \mathbf{3 b})$. Perceived behavior control is positively and significantly associated with purchase intention for organic clothing.

\subsection{Environmental Concern}

Environmental concern is defined as a "strong attitude to protect environment" by Crosby et al. [46]. Previous research has generally found that there is a positive relationship between environmental concern and purchase intention for green products [47,48]. Zhao et al. developed hypotheses based on classical literature, and conducted a case study from Qingdao, China, to explore the factors affecting green consumer behavior [48]. Environmental concern was recognized as one of the dominant cognitive constructs while predicting purchase intention for green products [49]. Higher environmental concern always leads to higher intention to protect the environment, and purchasing green products is an effective choice.

Sang and Bekhet demonstrated that environmental concern has a positive effect on purchase intention for a specific green product (i.e., electric vehicles) [50]. Yadav and Pathak concluded that environmental concern not only positively affected purchase intention for green products, but also positively affected the attitude toward such green products [13]. With an empirical investigation into Indian consumers, Jaiswal and Kant also found that environmental concern was positively associated with purchase intention for green products and attitude toward green products [49]. Besides, various previous research has combined this cognitive factor into the TPB framework. Chen and Tung combined environmental concern into an extended TPB framework and concluded that more positive environmental concern led to a more positive effect on attitude, subjective norms, and perceived behavior control toward visiting green hotels [33]. Similar results have been obtained from Paul et al. [34], who found that environmental concern was positively related to both purchase intention for green products and TPB constructs. Based on the review of the previous research, this study combined environmental concern with TPB. It not only considered the direct effect of environmental concern on TPB constructs, but also considered its different effects on different kinds of green products. The following hypotheses were developed based on the aforementioned discussion: 
Hypothesis 4a (H4a). Environmental concern is positively and significantly associated with attitude toward green products.

Hypothesis $4 \mathbf{b}(\mathbf{H} 4 \mathbf{b})$. Environmental concern is positively and significantly associated with subjective norms.

Hypothesis 4c (H4c). Environmental concern is positively and significantly associated with perceived behavior control.

Hypothesis 5a (H5a). Environmental concern is positively and significantly associated with purchase intention for energy efficient household appliances.

Hypothesis $\mathbf{5 b} \mathbf{( H 5 b ) . ~ E n v i r o n m e n t a l ~ c o n c e r n ~ i s ~ p o s i t i v e l y ~ a n d ~ s i g n i f i c a n t l y ~ a s s o c i a t e d ~ w i t h ~ p u r c h a s e ~ i n t e n t i o n ~}$ for organic clothing.

\subsection{Purchase Intention for Utilitarian and Hedonic Green Products}

Green products include various kinds of products, such as energy efficient household appliance, organic clothing, organic food, and electric vehicles. Some researchers have regarded green products as a general class to predict purchase intention [17,36], and others studied a specific green product [26,27]. However, few previous researchers have compared the different effects of constructs on different kinds of green products.

Based on purchase motives, Brijs et al. divided products into utilitarian products and hedonic products [28]. The motivation to buy hedonic products is hedonic and the motivation to buy utilitarian products is utilitarian. Costa et al. divided products into three classes, utilitarian nature-based products, utilitarian industrialized products, and hedonic industrialized products [29]. Three representative products-fruits, household appliances, and clothing-were chosen to evaluate the impact of country-of-origin on foreign products. Energy efficient household appliances are the green products that meet the energy consumption standards stipulated by the government for energy-saving products and are widely used because of their better practicability and environmental conservation ability. Organic clothing refers to the green products that can eliminate pollution, protect the environment, and maintain ecological balance during the whole process of raw material production, use, and recycle. They are harmless to health and are gradually becoming the consuming preference for environment protectors. Moreover, Costa et al. have demonstrated that household appliances are a kind of utilitarian products, and clothing is a kind of hedonic products [29]. Therefore, this study separates green products into two classes, and used energy efficient household appliances and organic clothing as representatives of utilitarian green products and hedonic green products respectively. Moreover, as indicated in these studies, cognitive factors can better promote forming purchase intention for utilitarian-oriented products, while affective factors can better promote forming purchase intention for hedonic-oriented products [29]. This study used energy efficient household appliances and organic clothing as representatives of utilitarian green products and hedonic green products respectively, and developed the following hypothesis:

Hypothesis 6 (H6). The effect of cognitive factor (i.e., environmental concern) toward purchase intention for utilitarian green products (i.e., energy efficient household appliance) is higher than the effect of hedonic green products (i.e., organic clothing).

In conclusion, TPB has been widely used and extended in purchase intention for green products. Whereas, most researchers regarded green products as a general class or only explored purchase intention for a specific green product, this study divided green products into two classes (i.e., utilitarian green products and hedonic green products) based on purchase motives, and examined the effects of TPB constructs and environmental concern on their purchase intention, respectively. Moreover, 
comparative effects of the cognitive factor were further probed for utilitarian green products and hedonic green products. Based on the aforementioned literature review, the conceptual framework of this study can be depicted as Figure 1.

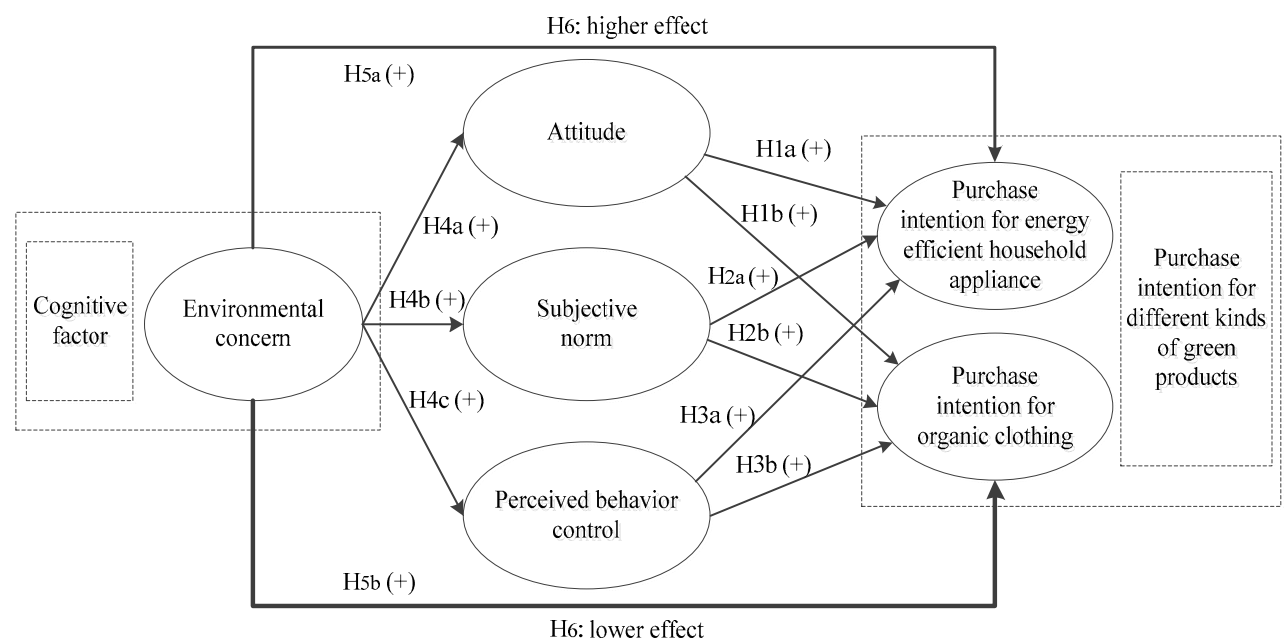

Figure 1. Proposed conceptual framework.

\section{Methodology and Measurement}

SEM has been widely used in psychology and behavior science, and covariance-based SEM and variance-based/component-based SEM are two prevalent methods. Recently, with the advantage of smaller required sample size and its good adaptation for prediction, component-based SEM has been increasingly used in many studies $[17,25]$. SmartPLS is one of the representative tools for component-based SEM that uses a least-squares estimation procedure. Therefore, this study applied SmartPLS 2.0 [51] to analyze the data from an empirical survey.

\subsection{Research Measures}

According to previous research, a questionnaire with 7-point Likert scales was developed to measure latent variables, wherein " 1 " represents "entirely disagree", and " 7 " represents "entirely agree". The items were developed based on previous literature and the details of the questionnaire are illustrated in Table 1.

The items for purchase intention were adapted from Taylor and Todd [52], and Wu and Chen [12], indicating the purchase intention for two kinds of green products. One was energy efficient household appliances representing a specific kind of utilitarian green products, and the other was organic clothing that represents a specific kind of hedonic green products. In previous research, household appliances have been defined as a kind of utilitarian product, and clothing has been defined as a kind of utilitarian product based on their different purchase motives [28,29]. Therefore, in this study, the energy efficient household appliances and organic clothing were classified as utilitarian green products and hedonic green products, respectively. Three items adapted from Taylor and Todd [52], and Jaiswal and Kant were employed to express consumers' attitude toward purchasing green products that reflect favor or disfavor of consumers to purchase green products [49]. Subjective norm items were also adapted from Taylor and Todd [52] and Jaiswal and Kant [49], indicating whether perceived social pressure from society and intimate people are important for the individual to choose green products. Perceived behavioral control items were adapted from Armitage and Conner [53] and Kim and Han [54], indicating the ease or difficulty (e.g., cost of time, money, and other resources) to purchase green products. Moreover, three items representing environmental concern were adapted from Armitage and Conner [53] and Kim and Han [54], which express how people are concerned about environmental problems and their willingness to support efforts to solve them. 
Table 1. Items for each construct.

Purchase intention (Adapted from Taylor and Todd [52]; Wu and Chen [12])

(1) For organic clothing

I intend to purchase organic clothing in my next purchase.

I would like to purchase organic clothing.

I would like to consider purchasing organic clothing first.

I would like to recommend others to purchase organic clothing.

(2) For energy efficient household appliances

I intend to purchase energy efficient household appliances in my next purchase.

I would like to purchase energy efficient household appliances.

I would like to consider purchasing energy efficient household appliances first.

I would like to recommend others to purchase energy efficient household appliances.

Attitude (Adapted from Taylor and Todd [52]; Jaiswal and Kant [49])
Purchasing green products is a good idea.
Purchasing green products is a wise idea.
Purchasing green products would be pleasant.
My society expects me to purchase green products.
Subjective norm (Adapted from Taylor and Todd [52] Jaiswal and Kant [49])
I value the opinion and feeling of my family on purchasing green products.
I value the opinion and feeling of my friends on purchasing green products.
Perceived behavioral control (Adapted from Armitage and Conner [53]; Kim and Han [54])
I can participate in the decision-making process of purchasing green products.
I can decide whether to purchase green products or not by myself.
I am free to choose green products when purchasing.
I have resources, time, and opportunities to purchase green products.
I am emotionally involved in environmental protection issues in China.
I often think about how the environmental quality in China can be improved.

\subsection{Translation and Pretesting}

The questionnaire was initially developed in English based on previous literature, and then translated into Chinese. A back-translation technique [55] was used to ensure the consistency between English and Chinese. First, a professor was invited to translate the questionnaire from English to Chinese; then another professor was invited to translate it from Chinese to English and compare it to the original English version; repeating translating until a consistency was achieved between English and Chinese. This process can avoid ambiguity caused by different languages and ensure the reliability of the questionnaire results from the source.

Furthermore, a pretesting process was employed to ensure the efficiency and effectiveness of the developed questionnaire. In this study, two steps were used to ensure the effectiveness of the questionnaire to the maximum extent. First, two professors were invited to examine the questionnaire and provide suggestions, so the questionnaire could be improved from a professional perspective; then, the questionnaire was distributed through 20 samples, and all these samples were randomly selected through the internet including different ages and educational levels. With the pretesting, minor revisions were made to improve the questionnaire.

Back-translation technique and pretesting processes can improve the effectiveness of the questionnaire to some extent and leading to more efficient survey data. Therefore, it built up a good foundation of experimental results and reasonable implications.

\subsection{Data Collection}

An online survey was applied to collect data with a prevalent online survey website [56]. It is a popular survey website that is widely used by researchers, students, and entrepreneurs in China. 
With the advantage of convenient distribution, fast spread speed, and convenient filling process, online surveys have been extensively used in previous research $[57,58]$. The data were collected from Southern region of China, because the economy in this region is prosperous, comparatively, and people are paying more and more attention to environmental protection these days. Therefore, a survey conducted in this region is more reasonable, and the collected data are more effective.

This study collected 223 valid samples after eliminating all outliers that were not up to standard (e.g., missing values and dishonest answers). Kline has advocated that ten samples for each item are enough to measure the latent variables, so required samples in this study were $210(21 \times 10=210)$ considering that there are 21 items in this study [59]. In addition, component-based PLS is fit for evaluating small sample size, so the data used in this study were efficient and sufficient. As shown in Table 2, the samples consist of 81 male participants and 142 female participants, $96.14 \%$ of whom had a bachelors' degree or higher. As demonstrated by some empirical research, people with high educational level are more likely to participate in green consumption. Moreover, $84.30 \%$ of participants had experience with purchasing energy efficient household appliances, while only $26.91 \%$ of participants had experience with purchasing organic clothing. This phenomenon reflects the different purchase intentions for different kinds of green products to some extent.

Table 2. Sample characteristics.

\begin{tabular}{cccc}
\hline Variables & Categories & Frequency & Percentage (\%) \\
\hline Gender & Male & 81 & 63.68 \\
& Female & 142 & 36.32 \\
\hline Age & Less than 18 years & 3 & 1.35 \\
& $18-25$ & 111 & 49.78 \\
& $26-35$ & 85 & 38.12 \\
& $36-45$ & 8 & 3.59 \\
& $46-55$ & 13 & 5.83 \\
Educational level & Above 55 & 3 & 1.35 \\
& High school or lower & 9 & 3.86 \\
& Bachelor & 138 & 59.23 \\
& Master & 74 & 31.76 \\
& PhD or higher & 2 & 0.86 \\
\hline Purchase experience1 & Yes & 188 & 84.30 \\
& No & 35 & 15.70 \\
\hline Purchase experience2 & Yes & 60 & 26.91 \\
& No & 163 & 73.09 \\
\hline
\end{tabular}

Note: Purchase experience1 represents the purchase experience for energy efficient household appliances; Purchase experience 2 represents the purchase experience for organic clothing. The percentages were calculated based on total usable sample of 223.

\section{Data Analysis and Results}

In this section, three parts of data analysis are elaborated to evaluate the experimental performance and the model efficiency. First, a two-step common method bias is used to analyze if there was any common variance problem. Second, reliability and validity of the proposed model are evaluated. Finally, hypotheses testing results are analyzed to verify the proposed conceptual framework.

\subsection{Common Method Bias}

Common method bias is a systematic error of self-reported data that is caused by the same data sources, same survey context, and the characteristics of the project [60]. Therefore, some statistical analysis is required to examine common method bias problems after preliminary procedural remedy to ensure the efficiency of the data.

This study applied a two-step verification to eliminate serious common method bias. First, Harman's single-factor test was performed using SPSS 22.0. Results from this test showed that the most covariance explained by one factor was $17.9 \%$, indicating that common method bias was not 
seriously affecting the sample data [60]. Second, following Liang et al., a common method factor that contains all indicators of constructs was included in PLS to measure each indicator's variance substantively explained by the principal construct and by the method [61]. As shown in Table 3, average substantive factors explained that the variance of the constructs was 0.9201 , while the average method-based variance only explained 0.0019 variance of the constructs. The ratio between substantive factor variance and method-based variance was 484:1. Moreover, as indicated in Table 3, all substantive factor loadings were significant, while most method factor loadings were insignificant. Based on these results, common method bias was not serious and unlikely to affect analysis results in this study. The two-step verification could explain that common method bias was not serious to a greater extent.

Table 3. Common method bias.

\begin{tabular}{|c|c|c|c|c|c|}
\hline Constructs & Items & $\begin{array}{l}\text { Substantive Factor } \\
\text { Loading (R1) }\end{array}$ & $\mathrm{R} \mathbf{1}^{2}$ & $\begin{array}{l}\text { Method Factor } \\
\text { Loading (R2) }\end{array}$ & $\mathrm{R} 2^{2}$ \\
\hline \multirow[t]{4}{*}{ INT1 } & INT11 & $0.9395 * * *$ & 0.8827 & 0.0005 & 0.0000 \\
\hline & INT12 & $1.0303^{* * *}$ & 1.0615 & $-0.1036^{* * *}$ & 0.0107 \\
\hline & INT13 & $0.9299^{* * *}$ & 0.8647 & 0.0172 & 0.0003 \\
\hline & INT14 & $0.8536^{* * *}$ & 0.7286 & $0.0874^{* * *}$ & 0.0076 \\
\hline \multirow[t]{4}{*}{ INT2 } & INT21 & $0.9280^{* * *}$ & 0.8612 & 0.0283 & 0.0008 \\
\hline & INT22 & $0.9496^{* * *}$ & 0.9017 & -0.0061 & 0.0000 \\
\hline & INT23 & $0.9660^{* * *}$ & 0.9332 & -0.0082 & 0.0001 \\
\hline & INT24 & $0.9722 * * *$ & 0.9452 & -0.0137 & 0.0002 \\
\hline \multirow[t]{3}{*}{ ATT } & ATT1 & $0.9547^{* * *}$ & 0.9115 & -0.0167 & 0.0003 \\
\hline & ATT2 & $0.9829 * * *$ & 0.9661 & $-0.0510 * *$ & 0.0026 \\
\hline & ATT3 & $0.8695^{* * *}$ & 0.7560 & $0.0681^{* *}$ & 0.0046 \\
\hline \multirow[t]{3}{*}{ SBN } & SBN1 & $0.8823^{* * *}$ & 0.7785 & 0.0034 & 0.0000 \\
\hline & SBN2 & $0.9615^{* * *}$ & 0.9245 & -0.0175 & 0.0003 \\
\hline & SBN3 & $0.9413 * * *$ & 0.8860 & 0.0142 & 0.0002 \\
\hline \multirow[t]{4}{*}{ PBC } & PBC1 & $0.7890^{* * *}$ & 0.6225 & 0.0663 & 0.0044 \\
\hline & PBC2 & $0.9357^{* * *}$ & 0.8755 & -0.0251 & 0.0006 \\
\hline & РBC3 & $0.8949^{* * *}$ & 0.8008 & 0.0253 & 0.0006 \\
\hline & PBC4 & $0.8106^{* * *}$ & 0.6571 & -0.0768 & 0.0059 \\
\hline \multirow[t]{3}{*}{ ENC } & ENC1 & $0.9341^{* * *}$ & 0.8725 & -0.0137 & 0.0002 \\
\hline & ENC2 & $0.8999^{* * *}$ & 0.8098 & 0.0237 & 0.0006 \\
\hline & ENC3 & $0.8974^{* * *}$ & 0.8053 & -0.0105 & 0.0001 \\
\hline Average & & 0.9201 & 0.8498 & -0.0004 & 0.0019 \\
\hline
\end{tabular}

Note: INT1 represents purchase intention for energy efficient household appliances, and INT11-INT14 are observation variables for INT1; INT2 represents purchase intention for organic clothing, and INT21-INT24 are observation variables for INT2; ATT represents attitude toward purchasing green products, and ATT1-ATT3 are observation variables for ATT; SBN represents subjective norm, and SBN1-SBN3 are observation variables for SBN; $\mathrm{PBC}$ represents perceived behavioral control, and $\mathrm{PBC} 1-\mathrm{PBC} 4$ are observation variables for $\mathrm{PBC}$; ENC represents environmental concern, and ENC1-ENC3 are observation variables for ENC; the above notes are also applied in the subsequent tables. ${ }^{* *} p<0.01,{ }^{* * *} p<0.001$.

\subsection{Reliability and Validity of the Model}

Three commonly used indicators, that is, individual reliability of items, composite reliability of latent variables, and average variance extracted of the latent variables were used to measure the reliability and validity of the model [25,62]. These indicators, on the one hand, verify whether the items can accurately reflect latent variables, and on the other hand, verify the convergent validity and the discriminant validity of the proposed model.

Factor loading of each item reflects the statistical significance of each item to test respective latent variables. As indicated by Hair et al. [63], the validity threshold of standardized factor loadings values is 0.5 , which can demonstrate a valid reflection for the latent variable. As shown in Table 4 , the factor loading of each item ranged from 0.7468 to 0.9617 , which showed high individual item reliability. 
Composite reliability (CR) indicates the internal consistency of the constructs, which is extensively used for checking convergence validity. The measurement of CR shown in Table 4 ranged from 0.9174 to 0.9759 , which was higher than the recommended threshold 0.7 [64]. Moreover, Cronbach's $\alpha$ is one of the most commonly used methods for reliability analysis in social science research. Cronbach's $\alpha$ for construct value ranged from 0.8784 to 0.9671 , surpassing the recommended threshold 0.7. Average variance extracted (AVE) is a statistical measure that examines the internal consistency of structural variables. AVE of each construct ranged from 0.7364 to 0.9101 , which was higher than the recommended threshold 0.5 [64]. All of these indicators demonstrated that the proposed model was reliable and valid.

Table 4. Reliability of scales and convergent validity.

\begin{tabular}{|c|c|c|c|c|c|}
\hline Constructs & Items & Factor Loadings & Cronbach's $\alpha$ & CR & AVE \\
\hline \multirow[t]{4}{*}{ INT1 } & INT11 & 0.9383 & 0.9550 & 0.9673 & 0.8810 \\
\hline & INT12 & 0.9468 & & & \\
\hline & INT13 & 0.9446 & & & \\
\hline & INT14 & 0.9246 & & & \\
\hline \multirow[t]{4}{*}{ INT2 } & INT21 & 0.9496 & 0.9671 & 0.9759 & 0.9101 \\
\hline & INT22 & 0.9445 & & & \\
\hline & INT23 & 0.9602 & & & \\
\hline & INT24 & 0.9617 & & & \\
\hline \multirow[t]{3}{*}{ ATT } & ATT1 & 0.9404 & 0.9290 & 0.9548 & 0.8757 \\
\hline & ATT2 & 0.9418 & & & \\
\hline & ATT3 & 0.9251 & & & \\
\hline \multirow[t]{3}{*}{ SBN } & SBN1 & 0.8846 & 0.9199 & 0.9496 & 0.8628 \\
\hline & SBN2 & 0.9487 & & & \\
\hline & SBN3 & 0.9517 & & & \\
\hline \multirow[t]{4}{*}{ PBC } & PBC1 & 0.8483 & 0.8784 & 0.9174 & 0.7364 \\
\hline & PBC2 & 0.9128 & & & \\
\hline & PBC3 & 0.9138 & & & \\
\hline & PBC4 & 0.7468 & & & \\
\hline \multirow[t]{3}{*}{ ENC } & ENC1 & 0.9227 & 0.8967 & 0.9356 & 0.8289 \\
\hline & ENC2 & 0.9196 & & & \\
\hline & ENC3 & 0.8886 & & & \\
\hline
\end{tabular}

Note: CR is abbreviation of composite reliability; AVE is abbreviation of average variance extracted.

As indicated in Table 5, the square root of AVE for each construct was greater than the highest correlation between the specific construct and other constructs, indicating a good discriminant validity [64]. Although the correlation between constructs ranged from 0.3716 to 0.6354 , and some constructs were more comparatively highly correlated to other constructs (e.g., INT1 and ATT, ENC and $\mathrm{PBC}$ ), the square root of AVE for each construct ranged from 0.8581 to 0.9540 , verifying an adequate discriminant validity.

Table 5. Discriminant validity.

\begin{tabular}{ccccccc}
\hline & INT1 & INT2 & ATT & SBN & PBC & ENC \\
\hline INT1 & $\mathbf{0 . 9 3 8 6}$ & & & & & \\
INT2 & 0.4991 & $\mathbf{0 . 9 5 4 0}$ & & & & \\
ATT & 0.6354 & 0.5548 & $\mathbf{0 . 9 3 5 8}$ & & & \\
SBN & 0.3716 & 0.4458 & 0.4118 & $\mathbf{0 . 9 2 8 9}$ & & \\
PBC & 0.5355 & 0.4965 & 0.5454 & 0.5103 & $\mathbf{0 . 8 5 8 1}$ & $\mathbf{0 . 9 1 0 4}$ \\
ENC & 0.5515 & 0.4909 & 0.5284 & 0.5596 & 0.6102 & \\
\hline
\end{tabular}




\subsection{Hypothesis Testing}

According to Table 6, attitude toward purchasing green products was positively and significantly correlated to purchase intention for energy efficient household appliances and organic clothing with a coefficient of 0.43 and 0.34 , respectively. The results indicated that the direct effects of attitude on purchase intention for different kinds of green product were a little different but not incommensurable. Hence, $\mathrm{H} 1 \mathrm{a}$ and $\mathrm{H} 1 \mathrm{~b}$ were supported. Perceived behavioral control was positively and significantly correlated to purchase intention for energy efficient household appliances and organic clothing with a coefficient of 0.17 and 0.15 , respectively. The coefficients of these two paths were almost the same, indicating a similar magnitude of effect on purchase intention for different green product classes. Moreover, the effect of attitude was higher than that of perceived behavioral control on both kinds of green products, consistent with the results of the previous literature that demonstrated that attitude toward green products will have the highest positive effect on the green purchase intention among all TPB predictor constructs [17]. Hence, H2a and H2b were supported. Subjective norm had a positive and significant effect on purchase intention for organic clothing, while it had a negative but insignificant effect on purchase intention for energy efficient household appliances. There was no consensus about how subjective norms affect purchase intention for green products. Some previous literature has verified that it had a positive effect on purchase intention for green products [12,26], while some researchers found that it had a negative effect $[65,66]$. Hence, H3b was supported, while H3a was not supported.

Table 6. Structural equation modeling (SEM) results of the extended theory of planned behavior (TPB) model.

\begin{tabular}{ccccccc}
\hline Paths & $\begin{array}{c}\text { Coefficients } \\
(\boldsymbol{\beta})\end{array}$ & $\mathbf{t}$-Value & Direct Effect & $\begin{array}{c}\text { Indirect } \\
\text { Effect }\end{array}$ & Total Effect & $\begin{array}{c}\text { Hypothesis } \\
\text { Supported }\end{array}$ \\
\hline ATT $\rightarrow$ INT1 & 0.43 & $12.196^{* * *}$ & 0.428 & - & 0.428 & Yes \\
ATT $\rightarrow$ INT2 & 0.34 & $11.182^{* * *}$ & 0.338 & - & 0.338 & Yes \\
SBN $\rightarrow$ INT1 & -0.02 & $0.775^{\mathrm{ns}}$ & -0.023 & - & -0.023 & No \\
SBN $\rightarrow$ INT2 & 0.15 & $4.489^{* * *}$ & 0.155 & - & 0.155 & Yes \\
PBC $\rightarrow$ INT1 & 0.17 & $4.591^{* * *}$ & 0.171 & - & 0.171 & Yes \\
PBC $\rightarrow$ INT2 & 0.15 & $4.068^{* * *}$ & 0.152 & - & 0.152 & Yes \\
ENC $\rightarrow$ ATT & 0.53 & $23.385^{* * *}$ & 0.528 & - & 0.528 & Yes \\
ENC $\rightarrow$ INT1 & 0.23 & $6.206^{* * *}$ & 0.234 & 0.318 & 0.552 & Yes \\
ENC $\rightarrow$ INT2 & 0.13 & $3.598^{* * *}$ & 0.133 & 0.358 & 0.491 & Yes \\
ENC $\rightarrow$ PBC & 0.61 & $29.073^{* * *}$ & 0.610 & - & 0.610 & Yes \\
ENC $\rightarrow$ SBN & 0.56 & $23.500^{* * *}$ & 0.560 & - & 0.560 & Yes \\
\hline
\end{tabular}

Note: ${ }^{* *} p<0.001$; ns represents this hypothesis is not supported.

In order to demonstrate the effectiveness of the proposed model, this study conducted comparative experiments by separating the dependent variables (i.e., purchase intention for organic clothing and that for energy efficient household appliances) and running the model two times. As indicated in Table 7, the coefficients of the paths were almost the same as those of the previous model, and the results of all hypotheses were also the same. Some slight differences were found in t-Values, but they did not affect the experimental conclusions. Therefore, the experimental results were reasonable and convincing.

Experimental results in Table 6 showed that environmental concern had a directly positive and significant effect on attitude, subjective norms, and perceived behavior control with a coefficient of 0.53 , 0.56 , and 0.61 respectively, so $\mathrm{H} 4 \mathrm{a}, \mathrm{H} 4 \mathrm{~b}$, and $\mathrm{H} 4 \mathrm{c}$ were supported. Moreover, environmental concern had a directly positive and significant effect on purchase intention for energy efficient household appliances and organic clothing with a coefficient of 0.23 and 0.13 , respectively. It also had an indirect effect on purchase intention for both kinds of green products, and the magnitude of indirect effect was almost the same with 0.318 and 0.358 , respectively. Hence, H5a and H5b were supported. In addition, the coefficients of 0.23 and 0.13 also indicated that cognitive factors had a higher effect on 
purchase intention for utilitarian green products (i.e., energy efficient household appliances) than that for hedonic green products (i.e., organic clothing). This verified that cognitive factors do have greater effect on hedonic green products than utilitarian green products, supporting $\mathrm{H} 6$.

In conclusion, hypothesis testing predicted $\mathrm{H} 1 \mathrm{a}, \mathrm{H} 1 \mathrm{~b}, \mathrm{H} 2 \mathrm{a}, \mathrm{H} 2 \mathrm{~b}, \mathrm{H} 3 \mathrm{~b}, \mathrm{H} 4 \mathrm{a}, \mathrm{H} 4 \mathrm{~b}, \mathrm{H} 4 \mathrm{c}, \mathrm{H} 5 \mathrm{a}, \mathrm{H} 5 \mathrm{~b}$, and $\mathrm{H} 6$ to be significant, whereas, $\mathrm{H} 3 \mathrm{a}$ was insignificant. The details of prediction results are presented in Table 6.

Table 7. Separating experimental results of the extended TPB model.

\begin{tabular}{ccccccc}
\hline Paths & $\begin{array}{c}\text { Coefficients } \\
(\boldsymbol{\beta})\end{array}$ & $\mathbf{t}$-Value & Direct Effect & $\begin{array}{c}\text { Indirect } \\
\text { Effect }\end{array}$ & Total Effect & $\begin{array}{c}\text { Hypothesis } \\
\text { Supported }\end{array}$ \\
\hline ATT $\rightarrow$ INT1 & 0.43 & $13.454^{* * *}$ & 0.429 & - & 0.429 & Yes \\
ATT $\rightarrow$ INT2 & 0.34 & $12.282^{* * *}$ & 0.340 & - & 0.340 & Yes \\
SBN $\rightarrow$ INT1 & -0.02 & $0.775^{\mathrm{ns}}$ & -0.023 & - & -0.023 & No \\
$\mathbf{S B N} \rightarrow$ INT2 & 0.15 & $4.313^{* * *}$ & 0.154 & - & 0.154 & Yes \\
$\mathbf{P B C} \rightarrow$ INT1 & 0.17 & $4.336^{* * *}$ & 0.171 & - & 0.171 & Yes \\
$\mathbf{P B C} \rightarrow$ INT2 & 0.15 & $4.091^{* * *}$ & 0.152 & - & 0.152 & Yes \\
ENC $\rightarrow$ ATT & 0.53 & $21.868^{* * *}$ & 0.529 & - & 0.529 & Yes \\
ENC $\rightarrow$ INT1 & 0.23 & $6.553^{* * *}$ & 0.233 & 0.319 & 0.552 & Yes \\
ENC $\rightarrow$ INT2 & 0.13 & $3.598^{* * *}$ & 0.133 & 0.358 & 0.491 & Yes \\
ENC $\rightarrow$ PBC & 0.61 & $30.687^{* * *}$ & 0.611 & - & 0.611 & Yes \\
ENC $\rightarrow$ SBN & 0.56 & $22.922^{* * *}$ & 0.559 & - & 0.559 & Yes \\
\hline
\end{tabular}

Note: ${ }^{* * *} p<0.001$; ns represents this hypothesis is not supported.

\section{Discussion of Findings and Implications}

In this study, the main purpose was to improve the understanding of purchase intention for green products by examining the effect of the extended TPB on different green products (i.e., utilitarian green products and hedonic green products). Two kinds of green products, that is, energy efficient household appliances and organic clothing, representing utilitarian green products and hedonic green products respectively, were used to verify the proposed hypotheses [29]. Moreover, a cognitive factor, that is, environmental concern was included to explore whether the magnitude of its effect differentiated between different kinds of green products. The direct and indirect effect of environmental concern were measured on different kinds of green products.

Prediction results indicated that TPB had significant effect on purchase intention for green products. To be specific, attitude and perceived behavior control had positive and significant effects on purchase intention for both utilitarian green products (i.e., energy efficient household appliances) and hedonic green products (i.e., organic clothing), as has also been demonstrated by Aman [67], and Hsu et al. [15], etc. Subjective norm had a positive and significant effect on purchase intention for organic clothing, while it had an insignificant effect on purchase intention for energy efficient household appliances. A consensus has not been formed about how subjective norm affects purchase intention for green products $[12,27,66]$. Environmental concern had a direct and positive effect on attitude, subjective norms, and perceived behavior control, as is consistent with the conclusions of previous research [34]. Moreover, environmental concern had a direct and significant effect on purchase intention for utilitarian green products (i.e., energy efficient household appliances) and hedonic green products (i.e., organic clothing), and the effect magnitude on utilitarian green products was higher than that on hedonic green products, as verified by Costa et al. [29] on imported products. Besides the direct effects, environmental concern also had indirect effects on purchase intention for both utilitarian and hedonic green products. The empirical experiments supported H1a, H1b, H2a, H2b, H3b, H4a, H4b, H4c, H5a, H5b, and H6, whereas, H3a was not supported, indicating that the proposed model is reasonable and efficient.

This study provides an insight for policymakers, entrepreneurs, and retailers to attract the attention of citizens toward environment protection and arouse the purchase intention for green products of the consumers. First, it is a theoretical exploration of extended TPB combined with cognitive factors, measuring different effects on utilitarian and hedonic green products; it provides an interesting and 
promising research perspective on purchase intention for green products by applying SEM methods. Second, policymakers could draw some policy implications to promote green consumption by citizens, thereby promoting environmental protection affairs. Efforts should be made to improve citizens' environmental concern by introducing relevant environmental protection policies and regulations, increasing the intensity of the media to promote environmental awareness, and improving public understanding of environmental protection policies and regulations. According to the findings of this study, environmental concern can not only directly improve purchase intention for green products, but also indirectly improve purchase intention by positively affecting the attitude toward green products, subjective norms, and perceived behavior control. This will certainly be advantageous to environmental protection. Third, entrepreneurs could make efforts to advertise the green products and their benefits to the environment so that consumers can better understand the green products they sell and form a positive attitude toward their green products. Positive attitude toward green products can promote purchase intention for green products. Propaganda for green products and environmental protection is conducive to the formation of the whole society's environmental protection context and hence improves the purchase intention for green products through social contact, which is verified by the fact that subjective norm was positively related to purchase intention for some green products (e.g., organic clothing). Fourth, perceived behavior control was positively correlated to purchase intention for green products, indicating that if green products are more accessible, the purchase intention for them will be higher. In this respect, retailers could make it easier for consumers to find the green products they need by setting clear slogans and providing more accessible shelving.

\section{Limitations and Future Research}

This study was mainly focused on verifying the effect of TPB constructs on purchase intention for green products. Moreover, a cognitive factor (i.e., environmental concern) was included to further analyze its different effects on different kinds of green products (i.e., utilitarian green products and hedonic green products). In this respect, this study provides a verification and extension for previous research that used TPB to examine purchase intention for green products, and proposes a research direction considering different effects of cognitive factors on different kinds of green products.

Although this study has covered some novel points, it still has some limitations that can be improved upon in future research. First, this study has separated the green products into two classes (i.e., utilitarian green products and hedonic green products) and selected energy efficient household appliances and organic clothing as representative products, but there are other classification standards and other utilitarian green products and hedonic green products that can be used to verify the proposed model. For example, Costa et al. separated products into three classes (i.e., utilitarian nature-based products, utilitarian industrialized products, and hedonic industrialized products) [29]. Further research can be done on different kinds of green products based on different classification standards and different kinds of utilitarian green products and hedonic green products. Second, cognitive factors is a comprehensive concept that contains various factors, and this study selected environmental concern as a representative to explore its different effects on different kinds of green products. In future work, other cognitive factors (e.g., environmental knowledge) can be used to explore how cognitive factors differently affect different kinds of green products. Third, limited data were used in this study although it meets the basic requirements of using PLS to study purchase intention for green products. Further research can be done based on a larger population so that it can cover more populations with different regions, occupations, and ages. Moreover, this study mainly focused on exploring the effect of TPB constructs and cognitive factors on different kinds of green products. Further research can be done by comparing different effects of constructs on different groups, such as male and female groups, groups with purchase experience, and without purchase experience. Fourth, owning to different green consumption habits, consumption levels, and supporting policies of green consumption, there are some differences in green consumption patterns between different regions. In our future work, cross-sectional research between two countries such as China and the USA can 
be developed to compare green consumption patterns between different regions. Fifth, this study considered the indirect effect (mediate effect) but had no regard for moderate effect of environmental concern. Further research can be done on this point to verify if the moderate effect of cognitive factors differentiates between different kinds of green products. Sixth, although some concepts are included in this study, other influential concepts (e.g., belief and value) could be included in further researches.

Author Contributions: Conceptualization, L.Z. and Y.F.; Data Curation, Y.F.; Formal Analysis, L.Z. and Y.F.; Funding Acquisition, W.Z. and S.Z.; Investigation, Y.F.; Methodology, L.Z. and Y.F.; Project Administration, L.Z., W.Z. and S.Z.; Supervision, W.Z.; Writing-Original Draft, L.Z. and Y.F.; Writing-Review \& Editing, W.Z. and S.Z.

Funding: This research was funded by National Natural Science Foundation of China grant number (No. 51875503, No. 51475410).

Conflicts of Interest: The authors declare no conflict of interest.

\section{References}

1. Haytko, D.L.; Matulich, E. Green advertising and environmentally responsible consumer behaviors: Linkages examined. J. Manag. Mark. Res. 2008, 1, 5-14.

2. Mcdougall, G.H.G. The green movement in Canada: Implications for marketing strategy. J. Int. Consum. Mark. 1993, 5, 69-87.

3. Shamdasani, P.; Chon-Lin, G.; Richmond, D. Exploring green consumers in an oriental culture: Role of personal and marketing mix. Adv. Consum. Res. 1993, 20, 488-493.

4. Sun, J.; Willson, V.L. Assessing general and specific attitudes in human learning behavior: An activity perspective and a multilevel modeling approach. Educ. Psychol. Meas. 2007, 68, 245-261. [CrossRef]

5. Kumar, B.; Manrai, A.K.; Manrai, L.A. Purchasing behaviour for environmentally sustainable products: A conceptual framework and empirical study. J. Retail. Consum. Serv. 2017, 34, 1-9. [CrossRef]

6. Chen, H.S.; Tsai, B.K.; Hsieh, C.M. Determinants of consumers' purchasing intentions for the hydrogen-electric motorcycle. Sustainability 2017, 9, 1447. [CrossRef]

7. Trope, Y.; Liberman, N. Temporal construal. Psychol. Rev. 2003, 110, 403-421. [CrossRef]

8. Fishbein, M.; Ajzen, I. Belief, Attitude, Intention, and Behavior: An Introduction to Theory and Research; Addison-Wesley Pub. Co.: Toronto, ON, Canada, 1975.

9. Bandura, A. Toward an agentic theory of the self. Adv. Self Res. 2008, 3, 15-49.

10. Ajzen, I. The theory of planned behavior. Organ. Behav. Hum. Decis. Process. 1991, 50, 179-211. [CrossRef]

11. Kim, Y.J.; Njite, D.; Hancer, M. Anticipated emotion in consumers' intentions to select eco-friendly restaurants: Augmenting the theory of planned behavior. Int. J. Hosp. Manag. 2013, 34, 255-262. [CrossRef]

12. Wu, S.I.; Chen, J.Y. A model of green consumption behavior constructed by the theory of planned behavior. Int. J. Mark. Stud. 2014, 6, 119-132. [CrossRef]

13. Yadav, R.; Pathak, G.S. Determinants of consumers' green purchase behavior in a developing nation: Applying and extending the theory of planned behavior. Ecol. Econ. 2017, 134, 114-122. [CrossRef]

14. Tanner, C.; Kast, S.W. Promoting sustainable consumption: Determinants of green purchases by Swiss consumers. Psychol. Mark. 2003, 20, 883-902. [CrossRef]

15. Hsu, C.L.; Chang, C.Y.; Yansritakul, C. Exploring purchase intention of green skincare products using the theory of planned behavior: Testing the moderating effects of country of origin and price sensitivity. J. Retail. Consum. Serv. 2017, 34, 145-152. [CrossRef]

16. Chen, S.C.; Hung, C.W. Elucidating the factors influencing the acceptance of green products: An extension of theory of planned behavior. Technol. Forecast. Soc. Chang. 2016, 111, 155-163. [CrossRef]

17. Sreen, N.; Purbey, S.; Sadarangani, P. Impact of culture, behavior and gender on green purchase intention. J. Retail. Consum. Serv. 2018, 41, 177-189. [CrossRef]

18. Eagly, A.H.; Chaiken, S. The Psychology of Attitudes; Harcourt Brace Jovanovich College Publishers: Fort Worth, TX, USA, 1993.

19. Workman, M. Expert decision support system use, disuse, and misuse: A study using the theory of planned behavior. Comput. Hum. Behav. 2005, 21, 211-231. [CrossRef]

20. Liao, C.; Chen, J.L.; Yen, D.C. Theory of planning behavior (TPB) and customer satisfaction in the continued use of e-service: An integrated model. Comput. Hum. Behav. 2007, 23, 2804-2822. [CrossRef] 
21. Chin, H.C.; Choong, W.W.; Alwi, S.R.W.; Mohammed, A.H. Using theory of planned behaviour to explore oil palm smallholder planters' intention to supply oil palm residues. J. Clean. Prod. 2016, 126, 428-439. [CrossRef]

22. Jiang, C.; Zhao, W.; Sun, X.; Zhang, K.; Zheng, R.; Qu, W. The effects of the self and social identity on the intention to microblog: An extension of the theory of planned behavior. Comput. Hum. Behav. 2016, 64, 754-759. [CrossRef]

23. Varshneya, G.; Pandey, S.K.; Das, G. Impact of social influence and green consumption values on purchase intention of organic clothing: A study on collectivist developing economy. Glob. Bus. Rev. 2017, 18, 478-492. [CrossRef]

24. Hua, L.; Wang, S.Y. Antecedents of consumers' intention to purchase energy-efficient appliances: An empirical study based on the technology acceptance model and theory of planned behavior. Sustainability 2019, 11, 2994. [CrossRef]

25. Yu, T.Y.; Yu, T.K.; Chao, C.M. Understanding Taiwanese undergraduate students' pro-environmental behavioral intention towards green products in the fight against climate change. J. Clean. Prod. 2017, 161, 390-402. [CrossRef]

26. Zhou, Y.F.; Thøgersen, J.; Ruan, Y.J.; Huang, G. The moderating role of human values in planned behavior: The case of Chinese consumers' intention to buy organic food. J. Consum. Mark. 2013, 30, 335-344. [CrossRef]

27. Nguyen, T.N.; Lobo, A.; Greenland, S. Pro-environmental purchase behaviour: The role of consumers' biospheric values. J. Retail. Consum. Serv. 2016, 33, 98-108. [CrossRef]

28. Brijs, K.; Bloemer, J.; Kasper, H. Country-image discourse model: Unraveling meaning, structure, and function of country images. J. Bus. Res. 2011, 64, 1259-1269. [CrossRef]

29. Costa, C.; Carneiro, J.; Goldszmidt, R. A contingent approach to country-of-origin effects on foreign products evaluation: Interaction of facets of country image with product classes. Int. Bus. Rev. 2016, 25, 1066-1075. [CrossRef]

30. Eagly, A.H.; Chaiken, S. The advantages of an inclusive definition of attitude. Soc. Cogn. 2007, 25, 582-602. [CrossRef]

31. Hines, J.; Hugerford, H.; Tomera, A. Analysis and synthesis of research on responsible environmental behavior. J. Environ. Educ. 1987, 18, 1-8. [CrossRef]

32. Han, H.; Hsu, L.T.; Sheu, C. Application of the theory of planned behavior to green hotel choice: Testing the effect of environmental friendly activities. Tour. Manag. 2010, 31, 325-334. [CrossRef]

33. Chen, M.F.; Tung, P.J. Developing an extended theory of planned behavior model to predict consumers' intention to visit green hotels. Int. J. Hosp. Manag. 2014, 36, 221-230. [CrossRef]

34. Paul, J.; Modi, A.; Patel, J. Predicting green product consumption using theory of planned behavior and reasoned action. J. Retail. Consum. Serv. 2016, 29, 123-134. [CrossRef]

35. Bamberg, S.; Möser, G. Twenty years after Hines, Hungerford, and Tomera: A new meta-analysis of psycho-social determinants of pro-environmental behaviour. J. Environ. Psychol. 2007, 27, 14-25. [CrossRef]

36. Hartmann, P.; Apaolaza-Ibáñez, V. Consumer attitude and purchase intention toward green energy brands: The roles of psychological benefits and environmental concern. J. Bus. Res. 2012, 65, 1254-1263. [CrossRef]

37. Yazdanpanah, M.; Forouzani, M. Application of the theory of planned behaviour to predict Iranian students' intention to purchase organic food. J. Clean. Prod. 2015, 107, 342-352. [CrossRef]

38. Sweeney, J.C.; Webb, D.; Mazzarol, T.; Soutar, G.N. Self-determination theory and word of mouth about energy-saving behaviors: An online experiment. Psychol. Mark. 2014, 31, 698-716. [CrossRef]

39. Thøgersen, J. Norms for environmentally responsible behaviour: An extended taxonomy. J. Environ. Psychol. 2006, 26, 247-261. [CrossRef]

40. Wu, K.S.; Man, T.Y. Applying the extended theory of planned behavior to predict the intention of visiting a green hotel. Afr. J. Bus. Manag. 2011, 5, 7579-7587.

41. Ajzen, I.; Madden, T.J. Prediction of goal-directed behavior: Attitudes, intentions, and perceived behavioral control. J. Exp. Soc. Psychol. 1986, 22, 453-474. [CrossRef]

42. Wang, P.; Liu, Q.; Yu, Q.I. Factors influencing sustainable consumption behaviors: A survey of the rural residents in China. J. Clean. Prod. 2014, 63, 152-165. [CrossRef]

43. Camilla, B.; Patrick, D.P. Positive and negative antecedents of purchasing eco-friendly products: A comparison between green and non-green consumers. J. Bus. Ethics 2016, 134, 229-247. 
44. Bong, K.S.; Jin, B. Predictors of purchase intention toward green apparel products: A cross-cultural investigation in the USA and China. J. Fash. Mark. Manag. Int. J. 2017, 21, 70-87. [CrossRef]

45. Arvola, A.; Vassallo, M.; Dean, M.; Lampila, P.; Saba, A.; Lähteenmäki, L.; Shepherd, R. Predicting intentions to purchase organic food: The role of affective and moral attitudes in the theory of planned behaviour. Appetite 2008, 50, 443-454. [CrossRef]

46. Crosby, L.A.; Gill, J.D.; Taylor, J.R. Consumer/voter behavior in the passage of the Michigan container law. J. Mark. 1981, 45, 19-32. [CrossRef]

47. Lin, P.C.; Huang, Y.H. The influence factors on choice behavior regarding green products based on the theory of consumption values. J. Clean. Prod. 2012, 22, 11-18. [CrossRef]

48. Zhao, H.H.; Gao, Q.; Wu, Y.P.; Wang, Y.; Zhu, X.D. What affects green consumer behavior in China? A case study from Qingdao. J. Clean. Prod. 2014, 63, 143-151. [CrossRef]

49. Jaiswal, D.; Kant, R. Green purchasing behaviour: A conceptual framework and empirical investigation of Indian consumers. J. Retail. Consum. Serv. 2018, 41, 60-69. [CrossRef]

50. Sang, Y.N.; Bekhet, H.A. Modelling electric vehicle usage intentions: An empirical study in Malaysia. J. Clean. Prod. 2015, 92, 75-83. [CrossRef]

51. Ringle, C.M.; Wende, S.; Will, A. SmartPLS-Version 2.0; University of Hamburg: Hamburg, Germany, 2005.

52. Taylor, S.; Todd, P.A. Understanding information technology usage: A test of competing models. Inf. Syst. Res. 1995, 6, 144-176. [CrossRef]

53. Armitage, C.J.; Conner, M. Distinguishing perceptions of control from self-efficacy: Predicting consumption of a low-fat diet using the theory of planned behavior. J. Appl. Soc. Psychol. 1999, 29, 72-90. [CrossRef]

54. Kim, H.Y.; Han, H. Intention to pay conventional-hotel prices at a green hotel-a modification of the theory of planned behavior. J. Sustain. Tour. 2010, 18, 997-1014. [CrossRef]

55. Usunier, J.C. International and Cross-cultural Management Research; SAGE Publications Ltd.: Thousand Oaks, CA, USA, 1998.

56. WJX. Available online: https://www.wjx.cn/ (accessed on 2 August 2019).

57. Cao, Y.Z.; Lu, Y.B.; Gupta, S.; Yang, S.Q. The effects of differences between e-commerce and m-commerce on the consumers' usage transfer from online to mobile channel. Int. J. Mob. Commun. 2015, 13, 51-70. [CrossRef]

58. Yang, S.Q.; Jiang, H.; Yao, J.R.; Chen, Y.G.; Wei, J. Perceived values on mobile GMS continuance: A perspective from perceived integration and interactivity. Comput. Hum. Behav. 2018, 89, 16-26. [CrossRef]

59. Kline, R.B. Principles and Practice of Structural Equation Modeling, 3rd ed.; The Guilford Press: New York, NY, USA, 2011.

60. Podsakoff, P.M.; Organ, D.W. Self-reports in organizational research: Problems and prospects. J. Manag. 1986, 12, 531-544. [CrossRef]

61. Liang, H.; Saraf, N.; Xue, H.Y. Assimilation of enterprise systems: The effect of institutional pressures and the mediating role of top management. MIS Q. 2007, 31, 59-87. [CrossRef]

62. Bagozzi, R.P.; Yi, Y. On the evaluation of structural equation models. J. Acad. Mark. Sci. 1988, 16, 74-94. [CrossRef]

63. Hair, J.F.; Black, W.C.; Babin, B.J.; Anderson, R.E.; Tatham, R.L. Multivariate Data Analysis; Pearson Prentice Hall: New Delhi, India, 2011.

64. Fornell, C.; Larcker, D.F. Evaluating structural equation models with unobservable variables and measurement error. J. Mark. Res. 1981, 18, 39-50. [CrossRef]

65. Connell, K.Y.H. Internal and external barriers to eco-conscious apparel acquisition. Int. J. Consum. Stud. 2010, 34, 279-286. [CrossRef]

66. Lee, K. The green purchase behavior of Hong Kong young consumers: The role of peer influence, local environmental involvement, and concrete environmental knowledge. J. Int. Consum. Mark. 2010, 23, $21-44$. [CrossRef]

67. Aman, A.H.L. The influence of environmental knowledge and concern on green purchase intention. The role of attitude as mediating variable. Br. J. Arts Soc. Sci. 2012, 7, 145-167.

(C) 2019 by the authors. Licensee MDPI, Basel, Switzerland. This article is an open access article distributed under the terms and conditions of the Creative Commons Attribution (CC BY) license (http://creativecommons.org/licenses/by/4.0/). 